\title{
Esfingolipidoak eta kolesterola, egitura lipidoak baino gehiago
}

\author{
(Sphingolipids and cholesterol, more than structural lipids)
}

\author{
Bingen G. Monasterio*, Aritz B. García-Arribas, Alicia Alonso, Felix M. Goñi \\ Instituto Biofisika (CSIC, UPV/EHU) eta Biokimika eta Biologia Molekularreko Saila, \\ Euskal Herriko Unibertsitatea (UPV/EHU).
}

\begin{abstract}
LABURPENA: Esfingolipidoek, beren buru polarrean dauzkaten talde polarren bidez, geruza bikoitzean existitzen diren beste lipido batzuekin sare konplexu bat eratzeko ahalmena daukate. Sare konplexu honen eraketa, - $\mathrm{OH}$ eta -NH- taldeekin hidrogeno-zubiak eratuz lortzen dute hain zuzen ere. Azken urteotan, lipido-urmaelaren hipotesiaren barruan, esfingomielinaren eta kolesterolaren arteko elkarrekintza espezifikoa asko ikertzen ari da, eta ikerketa honen emaitza da, estres-egoeren aurrean, zelulen mintzetan, esfingomielina-zeramida konplexuak sortzen direla proposatu izana. Gainera, kolesterol-zeramida elkarrekintzak ere gertatzen direla erakusten duten artikuluak gero eta ugariagoak dira. Existitzen diren esfingolipido moten inguruan jartzen ari den arretak gaiaren inguruko jakinduria handitzera garamatza. Izan ere, azkenaldian, deoxiesfingolipidoak bezalako esfingolipido aldakorren eta $\mathrm{N}$-azil katearen luzerak edota lipidoen asegabetze-mailek daukaten efektuaren inguruko ikerketa gehiago egiten ari dira. Aldakortasun horiek garrantzitsuak izan daitezke zeramidarekin lotutako droga terapeutiko edota gaixotasun ezberdinen tratamenduak garatzeko; horien artetik garrantzitsuenak minbiziarekin lotutako terapiak dira.
\end{abstract}

HITZ GAKOAK: Lipido domeinuak, esfingolipidoak, kolesterola, terapia.

ABSTRACT: Sphingolipids contain in their polar heads chemical groups allowing them to establish a complex network of $\mathrm{H}$-bonds through different - $\mathrm{OH}$ and $-\mathrm{NH}$ - groups with other lipids in the bilayer. In the recent years the specific interaction of sphingomyelin with cholesterol has been examined, largely in the context of the "lipid raft» hypothesis. Formation of sphingomyelin - Ceramide complexes, proposed to exist in cell membranes in response to stress, has also been described. In addition, data demonstrating direct Cholesterol-Ceramide interaction are becoming available. Finally, a more recent emphasis on the variability of sphingolipids is advancing our knowledge in the field, as more studies are performed on different variants of sphingolipids, such as deoxysphingolipids, and reports on the effects of the $\mathrm{N}$-acyl chain length or unsaturation are becoming available. This could be of importance in the currently growing field of developing ceramide-related therapeutic drugs or treatments for different illnesses, being the most relevant the cancer-related therapies.

KEYWORDS: Lipid domains; Sphingolipids, Cholesterol, therapy.

\footnotetext{
* Harremanetan jartzeko / Corresponding author: Bingen G. Monasterio, Instituto Biofisika (CSIC, UPV/EHU), Sarriena Auzoa, zg, (48940 Leioa, Bizkaia). Espainia. - bingen_gm@hotmail.com - https://orcid.org/0000-0002-8714-9427.

Nola aipatu / How to cite: Monasterio, Bingen G.; García-Arribas, Aritz B.; Alonso, Alicia; Goñi, Felix M. (2019). «Esfingolipidoak eta kolesterola, egitura lipidoak baino gehiago»; Ekaia, 36, 2019, 109-126. (https://doi.org/10.1387/ekaia.20791).

Jasoa: 15 apirila, 2019; Onartua: 3 uztaila, 2019.

ISSN 0214-9001 - elSSN 2444-3255 / (C) 2019 UPV/EHU

(c) (i) (-) Obra hau Creative Commons Atribución 4.0 Internacional-en

BY NC SA lizentziapean dago
} 
Bingen G. Monasterio, Aritz B. García-Arribas, Alicia Alonso, Felix M. Goñi

\section{SARRERA}

Azken urteotan zenbait lipido familiaren eginkizunak [1] eta horien eragin terapeutikoak [2] birplanteatu dira. Horien artean, esanguratsua da ikusi dela esfingolipidoen azpifamiliako zeramidek zerikusia izan dezaketela zelulen heriotza programatuan, nahiz eta heriotza horretarako mekanismoak ez diren oraindik guztiz ulertzen. Zenbait ikerketaren arabera, badirudi kate luzeko zeramidek -16 karbonokoek (C) (naturan ugarienak) edo luzeagoek - lipido-fase oso paketatuak sortzeko joera daukatela eta gainera albo-desplazamendu/banaketak eragiten dituztela. Albo-banaketa horien bidez, zeramidatan aberastutako domeinuak sortzen dira, eta horiek heriotza zelularra eragin dezaketen mekanismoekin lotuak egon daitezke [3].

Kolesterola animalien mintz plasmatikoetan dagoen eta egitura-funtzioa daukan lipidoa da. Gainera, jakina da mintzen jariakortasuna ere kontrolatzen duela. Kolesterola lipido-urmaelaren (lipid raft) hipotesian garrantzi handia daukan lipidoa da [4]. Urmael horiek kolesterolak eta esfingolipidoek momentu eta gune konkretuetan daukaten kontzentrazioigoeren ondorioz sortutako mintz-heterogeneotasunak dira. Urmael edo domeinu horiek, beren molekula maila oso ordenatua dela medio, esfingolipidoak eta proteina espezifikoak mintz bidezko garraioa arautu dezakete. Dena den, daukaten iraupen labur eta tamaina txikiaren ondorioz, ez da oraindik mintz heterogeneotasun hauek in vivo ikustea lortu.

Ikuspuntu fisiko-kimiko batetik, bai kolesterola, baita zeramida ere, buru polarrean hidroxilo talde bakarra daukaten egitura oso hidrofobikoak dira. Bi horiek, behin geruza bikoitzetan txertatuta, antzeko era batean antolatzen dira. Gainera, hainbat egoeratan, bien arteko albo-desplazamenduak gerta daitezkeela suposatzen da [5]

\section{ZERAMIDA TESTUINGURUAN: ESFINGOLIPIDOEN SEINALIZAZIOA}

Zeramidek bitartekari-lana dute zelulak estres-egoeren aurrean eman ditzakeen hainbat erantzunetan. Erantzun horien artean, apoptosia eta zelula seneszentzia [6] aurkitzen dira hain zuzen ere. Gainera, aipatutako eginkizunez gain, gaur egun, maila konplexuko beste hainbat esfingolipido bidezko seinalizazio ere deskribatzen ari dira [7, 8]. Konplexutasun hori lipido bioaktiboen arteko lotze metabolikotik (1. irudia), lipido baten egitura-aldaketak dauzkan efektu metaboliko ezberdinetara doa. Lotze metaboliko horren adibide da, hain zuzen ere, zeramida zeramida kinasa bidez zeramida-1-fosfatora eraldatua izan daitekeela eta azken honek jatorriko zeramidak zeuzkanen guztiz aurkako efektu edota eginkizunak dauzkala. Besteak beste, zelula ugalketan, hanturan eta zelula-biziraupenean garran- 
tzia izan dezakeela uste da [9]. Dena den, beste hainbat ikerketak erakutsi dutenaren arabera, hantura aurkako eginkizuna ere izan dezake [10]. Argi dago gaiaren inguruko desadostasun handiak existitzen direla eta horiei aurre egiteko ikerketa sakonagoak beharrezkoak direla.

Zeramida, zeramida-1-fosfatora eraldatzeaz gain, esfingosinara ere degrada daiteke. Esfingosina izan zen, hain zuzen ere, haren bioaktibitatea deskribatzea lortu zen lehen esfingolipidoa [11]. Zenbait ikerketaren arabera, esfingosinarekin eta esfingosinarekin harremana daukaten esfingo baseek endozitosia, ziklo zelularra, aktinazko zitoskeletoaren kontrola eta apoptosia arautzeko eginkizunak dituzte [12]. Beste ikerketa batzuen arabera, arteriosklerosiarekin ere izan dezakete loturaren bat [13].

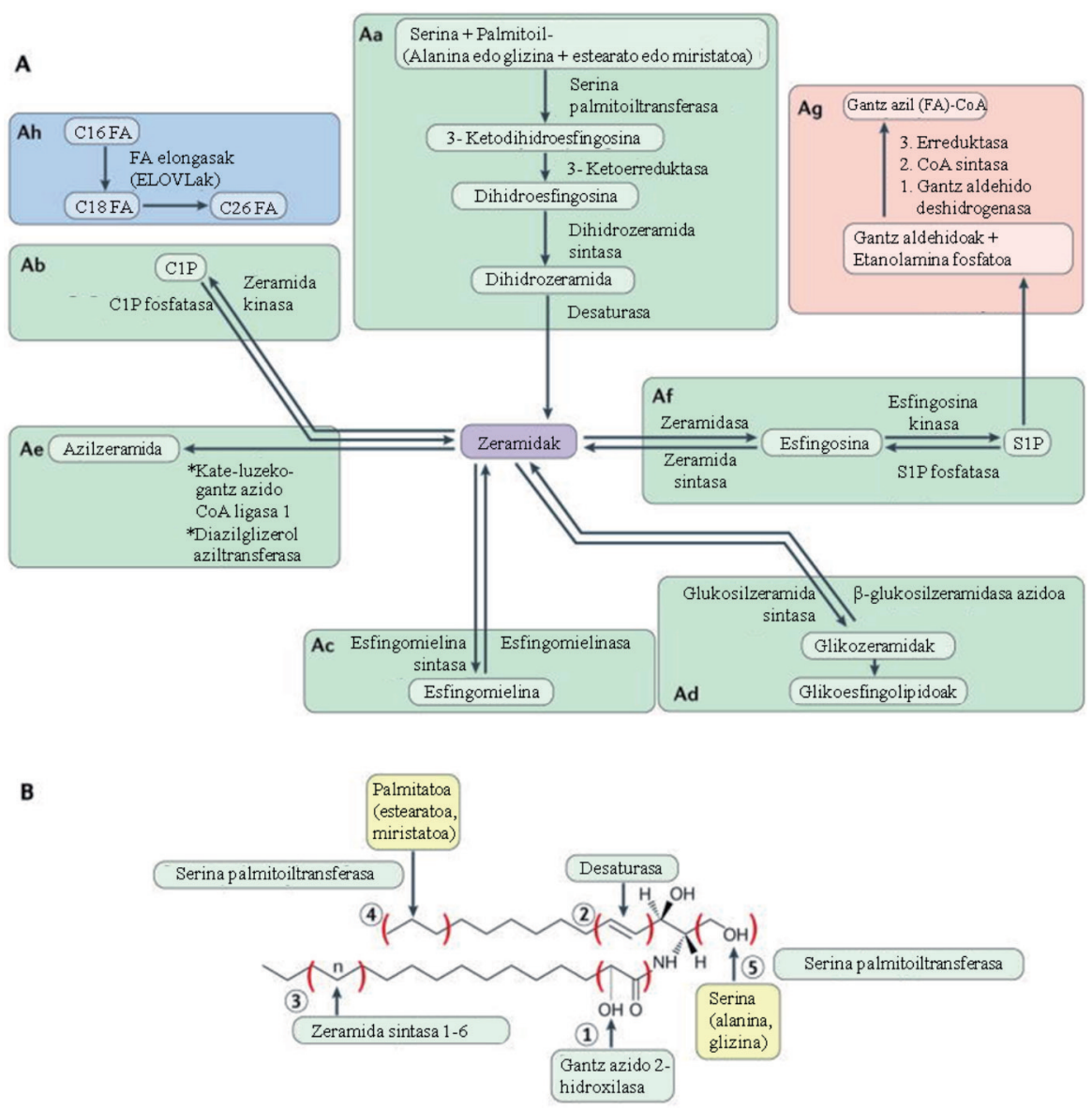

1. irudia. Esfingolipidoen metabolismoa (A) eta zeramidaren egitura (B). Hannun eta Obeid [6]-etik moldatua. 
Bingen G. Monasterio, Aritz B. García-Arribas, Alicia Alonso, Felix M. Goñi

Azkenaldiko hainbat artikulutan argitaratu denaren arabera, esfingolipidoen metabolismoaren aldaketak ikertuz eta aldaketa horiek oinarri gisa hartuz, minbizi-terapietan garrantzia izan dezaketen estrategiak sor litezke $[14,15]$. Gehienetan, terapia horiek gauzatzeko, ur-medio batean disolbagarriagoak diren kate laburreko C6-zeramidak [16] edota C2-zeramidak [17] erabiltzen dira.

Zenbait ikertzailek diotenaren arabera, esfingolipidoek prozesu mitotikoetan [18] eta glaukoma gaixotasunean [19] ere izan dezakete garrantzia. Aipatutakoa kontuan edukita, eragin metaboliko konplexuak sortzen dituzten eta esfingolipidoekin harremana daukaten konposatu natural berrien aurkikuntzan jar liteke arreta.

\section{ZERAMIDA: HILKORTASUN-ETENGAILUA ULERTZEKO SAIAKERA}

Zeramida apoptosian, zelula hazkuntzaren gelditzean, seneszentzian, diferentziazioan, erantzun immunean eta ziklo zelularra etetearen molekula mailako seinalizazioan eragina izan lezakeen esfingolipidoa da [20]. Duela hainbat hamarkadatatik, jakina da zeramidak esfingolipidoen metabolismoan bitartekari gisa jarduten duela. Dena den, laurogeiko hamarkadara arte ez zen frogatu zeramidak seinalizazio metaboliko garrantzitsuekin daukan lotura garrantzitsua $[11,21,22]$.

Zeramida oso kantitate baxuan aurkitzen da ugaztunen artean. Gainera, daukan muturreko hidrofobizitateak ur-medioan ia disolbagaitz egiten duenez, gehienbat mintzetan txertatua aurkitzen da. Hori da, hain zuzen ere, stratum corneumean, azal bidezko lurrunketa ekiditen duen mintzean, daukan ugaritasunaren arrazoi nagusiena [23].

Egiturari dagokionez, zeramidak luzera, asegabetze, eta hidroxilazio aldakorreko gantz-azido kate batez osatuak daude. Gantz-azido hori amida lotura baten bidez esfingo base baten amino talde batera lotua aurkitzen da. Zeramidak daukan gantz-azidoaren luzera 2 karbonotik 28 karbonora bitartekoa izan daiteke; dena den, ugaztunen artean, 16 eta 24 karbonokoak dira ugarienak. Gatz azido horiek, gehienetan, aseak edo monoasegabeak izan ohi dira, eta, batzuetan, $\mathrm{C} 2$ karbonoan ( $\alpha$-hidroxi gantz-azidoa) edota $\mathrm{C}$ amaieran ( $\omega$-hidroxi gantz-azidoa) hidroxilo talde bat eduki dezakete. Haien hidrofilizitate baxua dela eta, kate luzeko zeramida oso gutxitan aurkitzen da zitosolean; beste hitz batzuetan esanda, gehienetan zelula-mintzetan txertatua aurkitzen da.

Zeramidak zenbait bidezidorretatik sor daitezke: esfingomielinasa bidezko esfingomielinaren degradazio entzimatikoz edota, esfingosinatik abiatuz, zeramida sintasa edo zeramidasa eta tioesterasa neutralen konbi- 
Esfingolipidoak eta kolesterola, egitura lipidoak baino gehiago

nazio bidez [24]. Bidezidor horien estimulazio ezberdinen ondorioz, zeramidaren sorrera bultzatzea eta horrela gune espezifikoko kontzentrazioa ugaritzea lortzen da. Zenbait ikerketatan ikusi denez, bai esfigomielinasa azidoak, bai neutroak ezberdintasunak dauzkate beren ioi-dependentzian, pH optimoan eta zelula barneko kokapenean [25]. Gainera, esfingomielinasak beste lipido batzuen presentzia bidez erregula daitezke. Izan ere, kardiolipina edota bis(monoazilglizero)fosfato lipido anionikoak esfingomielinasen aktibitate entzimatikoa aktibatzeko gai direla ikusi da. Aipatutakoaz gain, lipido okerdurak ere eragina izan dezake erregulazioan [26].

Hainbat laborategi-ikerketak iradokitzen dutenaren arabera, zeramiden eragin biologikoetako batzuk haien ezaugarri biofisiko bakarren ondoriozkoak dira. Azken 15 urteotan, mintz-ereduetan egindako ikerketen bidez, zeramidek mintzetan daukaten eginkizunaren inguruko informazio asko argitaratu da. Beste eragin batzuen artean, zeramidaren oso kontzentrazio baxuak (\% 2-3 mol), hainbat fosfolipidoz osatutako mintz batean, zeramidatan aberastutako gel-fase bat albora banatzeko nahikoa dela ikusi da [27]. Zeramidaren muturreko kontzentrazioek, berriz, \% 33tik gorako kontzentrazioek, besikulak ezegonkortzen dituzte [28]. Zeramida hidrofobikoek mintzaren interfasean urarekin izan lezaketen kontaktua ekiditeko, zeramida molekulek gantz-azidoen gunea betetzen dute, eta honen ondorioz sortzen diren domeinuetako lipidoek molekularteko paketatze handiagoa eta molekulen arteko mugimendu murriztua daukate.

Zeramidatan aberastutako domeinu horien presentziak eta egonkortasunak mintzean aurkitzen diren beste lipido guztien ordena molekularrean ere eragina dute. Izan ere, domeinuek, zeramidatan aberastuak badaude ere, mintz-ereduan aurkitzen diren beste lipidoen ratio ezberdinak ere bere baitan txertatuak dauzkate. Horrek geruza bikoitzaren iragazkortasuna handitzea dakar, eta, horrela, edukia edota solutuen fluxua areagotzea eragiten da $[29,30]$. Prozesu hori aurrera eramateko mekanismoak ez dira oraindik guztiz ulertzen: alde batetik, domeinuan zeharreko zeramidazko kanal/poroak iradoki dira [30]. Dena den, zeramida molekulek, zeramidatan aberastutako domeinuetan, bat-batean, poro toroide hipotetiko batean antolatzeko, energia-hesi (entropikoa) handi bati aurre egin beharko liekete. Beste alde batetik, hipotesi horren ordezko ideia bat proposatu da. Honen arabera, solutuaren fluxua geruza bikoitzaren egiturak dauzkan akatsen ondoriozkoa da. Akats horiek zeramidatan aberastutako domeinuen eta domeinu horiek inguratzen dituen fasearen arteko faseartean gertatuko lirateke. Hau da, bi faseen arteko paketamendu-maila ezberdinak eta geruza bikoitzaren barnean dauden lodiera-ezberdintasunak direla medio, fasearteko muga ez-eraginkor bat sortuko litzateke, zeinetatik solutuen fluxua gertatuko litzatekeen [31]. Zeramidak, fase ez-lamelarrak sortzeko daukan joera geruza bikoitza ezegonkortzeko faktore gehigarri bat litzateke; horrela, besikula barneko edukia kanporatzea erraztuko litzateke [32]. 
Bingen G. Monasterio, Aritz B. García-Arribas, Alicia Alonso, Felix M. Goñi

Aipatutako mintzean zeharreko solutu-fluxua areagotzeaz gain, kate luzeko zeramidek 3 efektu gehigarri dauzkate: (i) geruza bikoitzek okerdura negatiboa hartzea (alderantzizko fase hexagonal baten gisa) [32], (ii) flipflop mugimendua areagotzea [33] eta (iii) geruza bikotzaren barneko bolumen libreko guneak areagotzea [34]. Ezaugarri biofisiko berezi horiek, hain zuzen ere, zeramidak heriotza zelularra eragiteko daukan mekanismoarekin lotuak egon daitezke. Beraz, prozesua ondo ulertzeko informazio baliagarria eman lezakete $[35,36]$. Bestalde, kate laburreko zeramidak fosfolipidoekin hobeto nahasten dira, txertatuta dauden geruza bikoitzetan okerdura positiboa eragiten dute, eta geruza bikoitzaren iragazkortasuna edota mintzean zeharreko solutu-mugimendua areagotzeko ahalmen oso urria dute [37].

\section{LIPIDO-DOMEINUAK: KOLESTEROLA ETA LIPIDO-URMAELAREN HIPOTESIAREN GAUR EGUNGO EGOERA}

Azken 40 urteetan, mintz-ereduetan egin diren ikerketek albo-domeinuen sorreran zeresana daukaten oinarri garrantzitsuenak ulertzea erraztu dute. Mintzetako lipido-domeinuen sorrera oso lotua dago lipidoen ezaugarri fisikoen araberakoa den lipido-lipido elkarrekintzekin. Hirurogeita hamarreko hamarkadan, Chapman eta lankideek, ekortze-kalorimetria bereizgarria (DSC) erabiliz, ikusi zuten zenbait fosfatidilkolina ase ez direla nahaskorrak [38]. Ordutik, beste hainbat teknikatan oinarrituz, ikerketa askok zenbait lipidok albora banatzeko daukaten ahalmena erakutsi dute [39]. Gaur egun, ondo ulertzen da gantz-azido asedun lipidoek lipido-domeinuak sortzeko joera daukatela lipido asegabeekin nahasten direnean. Izan ere, gantz-azido aseek Van der Waals elkarrekintza sendoagoak gauzatzen dituzte; horien bidez, gel-fluido fase-trantsizioaren tenperatura altuak sortzen dira. Beraz, lipido aseak (16 C-koak edo luzeagoak), normalean, gel fasean aurkitu ohi dira 20-37 gradu zentigradu bitarteko tenperaturetan. Horrek azalduko luke, hain zuzen ere, lipido ase horiek lipido asegabeekin kontaktatzean gertatzen den albo-domeinuen sorrera. Lipido aseen artean, esfingosinara gantz-azido ase bat itsatsia daukan esfingomielinak, beste hainbat lipidorekin nahastean, albora banatzeko joera handia dauka. Mintz-ereduetan, urtze- tenperatura baxuko fosfolipidoekin nahastean sortutako esfingomielina eta kolesteroletan aberastutako likido antolatudun domeinuak albodomeinuen adibide interesgarria lirateke.

Lipido-urmaelaren hipotesiak, 1997an Simons eta Ikonenek proposatuak, eragin nabarmena izan zuen gaiaren inguruan [4]. Hipotesi horren arabera, zelula bizien mintzetan domeinu nanometrikoak egon daitezke. Domeinu horiek, in vitro egindako entseguetan mikroi batzuetako tamaina izan dezaketen arren (2. irudia), in vivo daukaten tamaina txikiaren eta exis- 
tentzia-denbora laburraren ondorioz, oraindik ez dira detektatu, ezta haiek kuantifikatzea lortu ere. Singer eta Nicolsonek ideia hori beren teorian plazaratu ez zutela kontuan izanda [40], Simons eta Ikonenen albo-banaketen ideia kontzeptu oso berritzaile bat izan zen. Azken urteotan, mosaiko jariakorraren eredua eredu berritzaile batera moldatua izan da, zeinetan kontzeptu berriak kontuan hartzen diren, hala nola albo-banatutako fasek, lipido asimetria edota proteina-proteina elkarrekintzak [41-43].
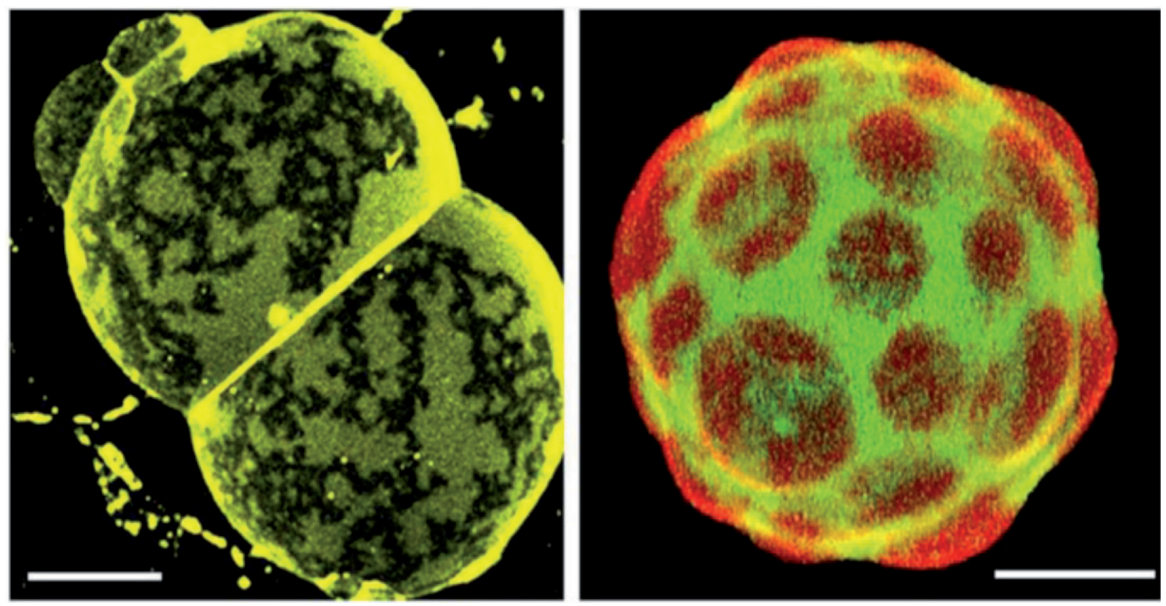

2. irudia. Mikroi batzuetako tamainako domeinua duten mintzen irudiak, mikroskopio konfokal bidez lortuak. Ezkerrean: gizakien azaleko stratum corneumeko lipidoz osatutako mintz naturala. Espezializatutako mintz honek 11 zeramida ezberdin, kolesterola eta kate luzeko (C24-C26) gantz-azidoak 1:0,9:0,4 mol ratioan dauzka. Bertan, gel motako bi fase bereiz daitezke [44]. Mintza DiIC ${ }_{18} \mathrm{z}$ markatua dago, $T=32^{\circ} \mathrm{C}$ (azaleko tenperatura fisiologikoa). Eskuinean: txerriaren birika surfaktanteko mintzak. Mintz espezializatu hori batez ere fosfolipidoz eta era bereizgarrian lotutako proteinez (SP-B eta SP-C) osatua dago. Fosfolipidoen artean, animalia-mintz gehienetan ezohikoak diren dipalmitoilfosfatidilkolina eta fosfatidilglizerola dauzka. Fosfatidilkolina monoasegabeak, fosfatidilinositola eta lipido neutroak (horien artean kolesterola) proportzio ezberdinetan ageri dira [45]. Mintz natural hau $\mathrm{DiIC}_{18} \mathrm{z}$ (gorria) eta Bodipy-PCz (berdea) markatua dago. Bertan, batera existitzen diren fase jariakor eta antolatua dauzka, $T=37^{\circ} \mathrm{C}$. Eskalabarrak $=10 \mu \mathrm{m}$. Bagatolli eta Mouritsen [43]-etik hartua.

Lipido-urmaelaren hipotesiaren arabera, lameladun likido-antolatuaren fasea, esfingomielinaren eta kolesterolaren arteko elkarrekintzaren lehentasunean oinarritzen da [46]. Hipotesi horren planteamenduaren aurretik, ideia hori, tradizionalki, azaldu da gantz-azidoen eta talde polarren bitartean kolesterolak betetzen dituen guneen bidez, eta geruza bikoitzetako geruza ezberdinen digitazio arteko gertakizunetan eragina izateko auke- 
Bingen G. Monasterio, Aritz B. García-Arribas, Alicia Alonso, Felix M. Goñi

raren arabera [47]. Dena den, existitzen den elkarrekintza garrantzitsuena bi molekularen arteko hidrogeno-lotura sendo baten bidez ere azal daiteke $[48,49]$. Esfingomielinaren eta kolesterolaren kasuan, horien arteko elkarrekintza eragiten duen indar garrantzitsuena esfingomielina molekularen amida taldearen eta kolesterolaren 3-hidroxil taldearen arteko hidrogeno-lotura bat dela dirudi [50]. Badirudi elkarrekintza hori ezinbestekoa dela, bai esfingomielinatan bai kolesteroletan aberastuak diren domeinu likido- antolatuak sortzeko.

Esfingomielinak daukan elkarrekintza-ahalmen handiak molekula horrek zeramidarekin daukan elkarrekintza estua ere azal lezake. Izan ere, zeramidak esfingomielinaren amida taldeko hidrogenoarekin lotura sor dezakeen hidroxilo taldeak dauzka. Badirudi esfingomielinak daukan zeramidarekiko edo kolesterolarekiko lehentasunak elkarren arteko alboratzeak gertatzea ahalbidetu lezakeela.

Lipido-urmaelaren hipotesiak arazoak ere badauzka barnean; izan ere, hipotesia in vivo egiaztatzeko eragozpen nabarmenak daude. Aurretik aipatu den bezala, arazo garrantzitsuenak domeinuen trantsizio-natura eta beraien tamaina nanometrikoak dira, mintz-ereduetan domeinu horiek mikroi batzuetako tamaina daukaten arren (2. irudia). Gainera, mintz ereduek ez bezala, zelula bizidunek zitoskeletoa edukitzeak ere zeresana izan lezake. Izan ere, zitoskeletoak domeinuen tamaina izugarri murriztuko luke, haien tamaina eskala nanometrikora eramanez [51]. Ideia hori azaltzeko, taket-hesi edota picket fence izeneko eredua proposatu da; horretan, aktina-sareak mintza konpartimentutan bananduko luke, eta, horrela, lipidoen alboratzea eragingo [52].

Esfingomielinaren eta kolesterolaren arteko lipido-lipido elkarrekintza guztiak ez dira urmael-sortzaileak. Kontuan eduki behar da esfingolipidoen artean bai esfingomielinen eta bai zeramiden egitura-aldaketa txikiak erabakigarriak izan daitezkeela beraien ezaugarri biofisikoentzat $[53,54]$. Esfingolipidoak eraldatuta ager daitezke, deoxiesfingolipido [55-57] edota dihidroesfingolipido [58] gisa, eta horien lipido-lipido elkarrekintza-ahalmenak ez dira oraindik ondo ezagutzen. Dena den, dagoen informazioaren arabera, badirudi egitura-aldaketa txikiak jasateak molekularen ezaugarri fisiko-kimikoetan eraldaketa handiak sor ditzaketela.

Mintz-ereduen bitartez, C24:1 esfingomielinak likido antolatudun domeinuetan disolbagarritasuna areagotzeko eragina daukala egiaztatu da; izan ere, beste lipido batzuk fase bakarrean barneratzen ditu [59] (3. irudia). Ikerketa horren arabera, animalia batzuen globulu gorrien erauzkinetan ere gertatzen da hori. Izan ere, ikertu diren erauzkinetatik batek ere ez du likido antolatuaren faserik sortzen, nahiz eta horietan C24:1 esfingomielina aurkitzen den. Beste lipido batzuek izan dezaketen disolbagarritasunefektua neurtzeko, disolbagarritasun-ugaritzea eta domeinu-sortzea eragiten duten lipidoen arteko ratioei buruzko ikerketa gehiago beharrezko dira. 


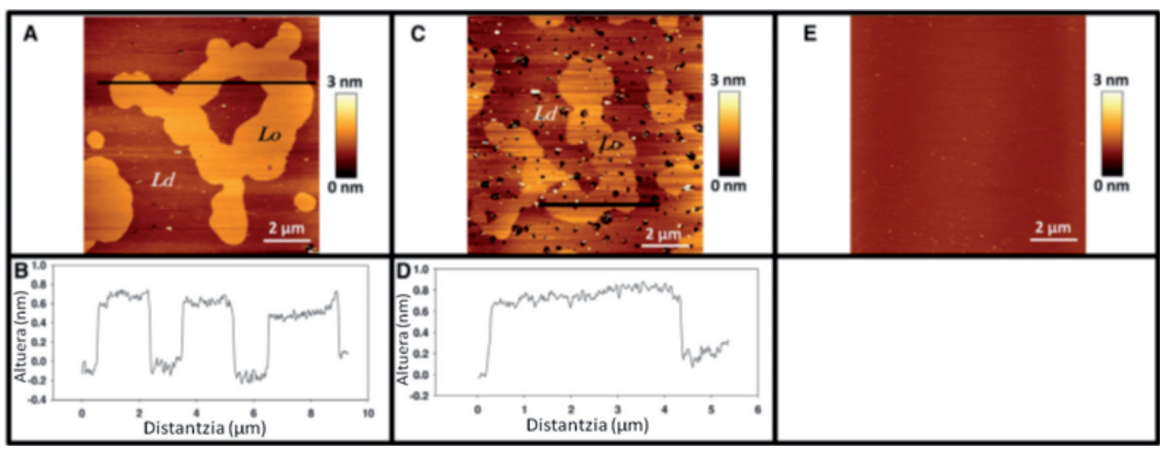

3. irudia. Geruza bikoitzeko lipidoen irudia topografikoak, indar atomikoko mikroskopio (AFM) bidez lortuak. (A) DOPC / 16:0 SM / kolesterola (2:1:1 ratio molarra). (B) A irudian agertzen den lerro beltzaren altuera-profila. (C) DOPC / 24:0 SM / kolesterola (2:1:1 ratio molarrean). (D) C irudian agertzen den lerro beltzaren altuera-profila. (E) DOPC / 24:1 SM / kolesterola (2:1:1 ratio molarra). E irudiak erakusten du ea 24:1 esfingomielinaren presentziak likido antolatuaren fasea alboratzea eragozten duen Maté et al. [59]-etik hartua.

\section{ZERAMIDATAN ABERASTUTAKO DOMEINUAK: IKUSPUNTU ZELULARRAK ETA GARRANTZI TERAPEUTIKOA}

Fosfolipidoz, zeramidaz eta kolesterolez sortutako geruza bikoitzetan zeramidatan aberastutako domeinuak agertzea geruza bikoitz horiek daukaten kolesterol kantitatearen menpekoa da. Agerpen hori, batez ere, bietako bat edota biak kantitate handian dudenean nabarmentzen da. Horrela bada, seinalizazio apoptosikoak bideratzen dituen prozesuetan, kolesterolaren eta zeramidaren arteko balantze kritiko batek modulatzaile gisa jardun lezake [60-62]. Gainera, jakina da zeramidak apoptosia erregulatzen duela, eta badirudi mitokondrien lipido-konposizioa guztiz aldatu ostean haien mintzean zeharreko zitokromo C oxidasaren fluxua gertatzen dela [63, 64]. Dena den, poro apoptosikoa sortzeko mekanismoak (bai lipido-lipido eta baita proteina-lipido modulazioak ere) oraindik argitu gabe daude [65].

Zelula-mintzetan ere, mintz-ereduetan gertatzen den antzera, zeramidak daukan alboratze-gaitasun handiak garrantzia izan dezake. Asetasunegoeretan, zeramidaren eta kolesterolaren arteko elkarrekintza positibo bat existi daiteke [66-68]. Kontuan eduki behar da, hortaz, sasoi batean globulu gorrien bero-hotz bidezko hemolisian zeramidatan aberastutako gisa deskribatu ziren domeinu haiek [69] kolesteroletan aberastuak diren geldomeinuak ere izan litezkeela. Izan ere, giza globulu gorrien mintz plasmatikoak kolesterol kantitate handiak (\% 40 molarretik gora) dauzka [70]. 
Bingen G. Monasterio, Aritz B. García-Arribas, Alicia Alonso, Felix M. Goñi

Kolesterol-kontzentrazio altuko egoera horietan, guneko zeramida-kontzentrazio altuen ondorioz, bai zeramidatan eta bai kolesteroletan aberastuak egon daitezkeen gel-faseak sor litezke[69]. Egoera hori dagoeneko azaldua da globulu gorrien lipido-erauzkinetan [71].

Garrantzitsua da aipatzea mitokondrietan ere egon litezkeela kolesteroletan eta zeramidatan aberastutako gel-domeinu konplexu halakoak. Mitokondrien kanpo-mintza kolesteroletan urria dela uste bada ere, azken hamarkadetako ikerketek erakutsi dutenez, kolesterolaren presentzia altuagoa izan daiteke zenbait gaixotasunen adierazgarri [72]. Berriki egin diren beste ikerketa batzuen arabera, kolesterola DNA mitokondrialaren bitartekaria izan daiteke $[73,74]$. Ikerketa batek dioenaren arabera, mitokondrien kanpo-mintzeko kolesterol-kontzentrazioaren ugaritzea kimioterapia bidezko heriotzaren erresistentziarekin lotua dago [75]. Hori kontuan izanda, kolesterol-zeramida orekaren hipotesiak garrantzia izan dezake honako bi ideiengatik: zeramida heriotza zelularraren prozesuekin lotua dago, eta estres-egoeran dauden mitokondrien mintzetan zeramidatan aberastutako domeinuak ageri dira [76]. Kolesterol kantitate handiago batek elkarrekintzak izango lituzke zeramidatan aberastutako domeinuekin, edo bai zeramidatan eta bai kolesteroletan aberastua dagoen beste era bateko fase bat sor lezake, zeinak, segur aski, zelularen seinalizazio-segidan efektu ezberdinak izango lituzkeen

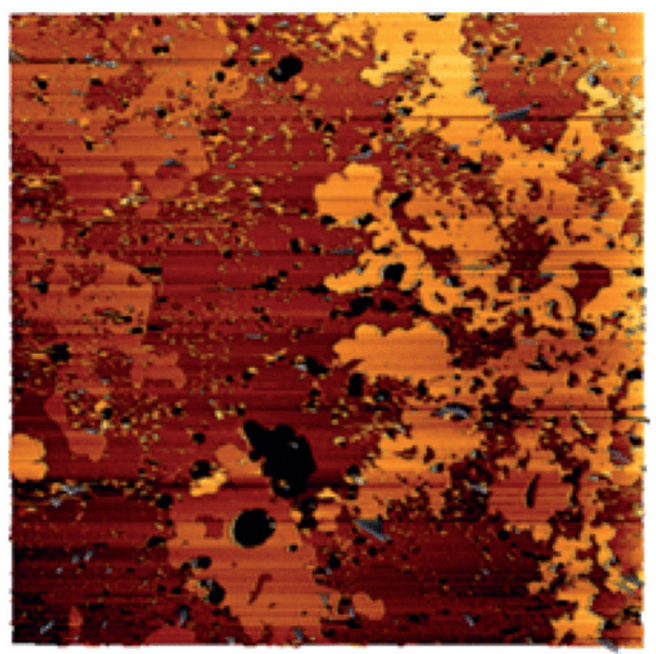

4. irudia. 16:0 zeramida eta 24:1 zeramida kontzentrazio molekular berberean dituen DOPC / 24:1 esfingomielina / kolesterol bidez sortutako mintz baten AFM bidezko irudia. Bi lipido-domeinu identifika daitezke, bietako bakoitza zeramida batean aberastua dago. Esfingolipido (eta batez ere zeramida) ezberdinek dauzkaten betebehar biofisikoen ebidentzia argia da hau. García-Arribas et al. [77]-etik hartua. 
Esfingolipidoak eta kolesterola, egitura lipidoak baino gehiago

Tumore aurkako gaur egungo terapiei dagokienez, hainbat esfingolipido lotu dira kimiorresistentzia-mekanismoarekin. Esfingomielinak eta glikoesfingolipidoak hainbat drogarekiko erresistentea den $\mathrm{ABCB} 1$ proteinarekin lotu dira. Lee eta Kolesnickek mintzean aurkitzen den esfingomielina, zeramida edota kolesterol eta drogak lotzeko eta garraiatzeko garrantzitsuak direla diruditen $\mathrm{ABCB} 1$ en mintzean zeharreko domeinuaren hainbat elkarrekintza-gune postulatu zituzten [78]. Esfingolipidoek DNA kaltetuaren erantzun-mekanismoan ere parte hartzen dute (gutxienez legamietan) [79]. Gainera, gibelean, drogen glutazio- eta detoxifikazio-prozesuetan ere zerikusia daukatela ikusi da [80]. Kimioterapia osteko zelula-ugaltzearen edota heriotza zelular murriztuaren inhibizio eskasaz arduratzen diren mekanismo molekularrak tumore identitatearen, pilatutako gene mutazioaren edota epigenetika bidezko geneeraldaketen menpekoak dira. Kimioterapia osteko heriotza zelularrarekin lotutako bidezidor garrantzitsuenak mekanismo apoptosikoa eta autofagikoa dira. Bi mekanismo horiek kinasaren, fosfatasaren, p53-aren eta beste batzuen eraginpean egon daitezke, eta esfingolipidoak, hain zuzen ere, aipatutako proteina horien erregulatzaile garrantzitsuak dira [15].

Hainbat argitalpenek maiz erakutsi dute esfingolipidoek zelulan dauzkaten efektuak esfingolipido mota ezberdinen menpekoak direla. Berriki argitaratu diren bi berrikuspenetan ongi laburbiltzen da esfingolipido ezberdin horiek minbizian izan dezaketen zelulen seinalizazioan nola eragiten duten $[6,81]$. Luzera eta asegabetze ezberdinetako zeramidek izan ditzaketen efektu biofisiko ezberdinak eta existi daitezkeen hainbat lipidodomeinuren aldi bereko existentzia kontuan edukiz (4. irudia), esfingolipidoen konplexutasuna eta haien efektuak era esponentzialean hazten ari dira. Gainera, azpifamiliak (deoxiesfingolipidoak, dihidroesfingolipidoak etab.) kontuan hartzen baditugu, atea irekitzen zaie horiek terapietan erabili ahal izateko aukera berriei.

\section{ONDORIOAK}

Laburbilduz, esparruko azken aurrerapenek erakusten dute zelulen mintzetan gero eta garrantzitsuagoak diruditela zeramidaren eta kolesterolaren arteko lipido-lipido elkarrekintzek, eta antzekoek. Dena den, azken hamarkadan, lipido-lipido elkarrekintza eta esfingolipido bidezko seinalizazioebidentzia gehienak mintz-ereduetan karakterizatu dira. Arrazoi horregatik, gaiaren inguruko ikerketa aurreratuenak eredu konplexuago batera eraman beharko lirateke, hau da, zelula-mintzetara edota in vivo eginiko esperimentuetara. Horrek egituraren (lipido faseen existentzia) eta funtzioaren (mintz-trafikoa eta seinalizazio zelularra) arteko erlazioa guztiz argituko luketen ereduak garatzen lagunduko luke. Gainera, espero da eredu horiek garrantzia izango dutela minbiziaren aurkako terapien inguruko jakinduria hobetzean eta tumoreen aurkako tratamenduen eragina handitzean. 
Bingen G. Monasterio, Aritz B. García-Arribas, Alicia Alonso,

Felix M. Goñi

\section{ESKER ONAK}

Lan hau FEDER MINECOk (BFU 2015-66306-P) eta Eusko Jaurlaritzak (IT-849-13) emandako dirulaguntzaren bidez egin da. Bingen G. Monasterio Euskal Herriko Unibertsitatearen bekaz diharduen doktorego aurreko ikaslea da.

\section{BIBLIOGRAFIA}

[1] CASTRO B.M., PRIETO M. eta SILVA L.C. 2014. «Ceramide: a simple sphingolipid with unique biophysical properties», Progress in lipid research, 54, 53-67.

[2] SAHU S.K., HANNUN Y.A. eta YAO N. 2019. «Emergence of membrane sphingolipids as a potential therapeutic target», Biochimie.

[3] GOÑI F.M. eta ALONSO A. 2009. «Effects of ceramide and other simple sphingolipids on membrane lateral structure», Biochimica et Biophysica Acta (BBA)-Biomembranes, 1788, 169-177.

[4] SIMONS K. eta IKONEN E. 1997. «Functional rafts in cell membranes», Nature, 387, 569-572.

[5] MEGHA eta LONDON E. 2004. «Ceramide selectively displaces cholesterol from ordered lipid domains (rafts): implications for lipid raft structure and function», The Journal of biological chemistry, 279, 9997-10004.

[6] HANNUN Y.A. eta OBEID L.M. 2018. «Sphingolipids and their metabolism in physiology and disease», Nature reviews Molecular cell biology, 19, 175.

[7] GARCIA-BARROS M., COANT N., TRUMAN J.P., SNIDER A.J. eta HANNUN Y.A. 2014. «Sphingolipids in colon cancer», Biochimica et biophysica acta, 1841, 773-782.

[8] GARCÍA-GONZÁLEZ V., DÍAZ-VILLANUEVA J., GALINDOHERNÁNDEZ O., MARTÍNEZ-NAVARRO I., HURTADO-URETA G. eta PÉREZ-ARIAS A. 2018. «Ceramide metabolism balance, a multifaceted factor in critical steps of breast cancer development», International journal of molecular sciences, 19, 2527.

[9] GÓMEZ-MUÑOZ A., GANGOITI P., ARANA L., OURO A., RIVERA I.G., ORDOÑEZ M. eta TRUEBA M. 2013. «New insights on the role of ceramide 1-phosphate in inflammation», Biochimica et biophysica acta, 1831, 1060-1066.

[10] LAMOUR N.F., WIJESINGHE D.S., MIETLA J.A., WARD K.E., STAHELIN R.V. eta CHALFANT C.E. 2011. «Ceramide kinase regulates the production of tumor necrosis factor alpha (TNFalpha) via inhibition of TNFalpha-converting enzyme», The Journal of biological chemistry, 286, 42808-42817. 
Esfingolipidoak eta kolesterola, egitura lipidoak baino gehiago

[11] HANNUN Y.A., LOOMIS C.R., MERRILL A.H., JR. eta BELL R.M. 1986. «Sphingosine inhibition of protein kinase $\mathrm{C}$ activity and of phorbol dibutyrate binding in vitro and in human platelets», The Journal of biological chemistry, 261, 12604-12609.

[12] ADADA M., CANALS D., HANNUN Y.A. eta OBEID L.M. 2014. «Sphingolipid regulation of ezrin, radixin, and moesin proteins family: implications for cell dynamics», Biochimica et biophysica acta, 1841, 727-737.

[13] JIMÉNEZ-ROJO N., VIGUERA A.R., COLLADO M.I., SIMS K.H., CONSTANCE C., HILL K., SHAW W.A., GOÑI F.M. eta ALONSO A. 2014. «Sphingosine induces the aggregation of imine-containing peroxidized vesicles», Biochimica et biophysica acta, 1838, 2071-2077.

[14] DAI L., XIA P. eta DI W. 2014. «Sphingosine 1-phosphate: a potential molecular target for ovarian cancer therapy?», Cancer investigation, 32, 71-80.

[15] MORAD S.A. eta CABOT M.C. 2013. «Ceramide-orchestrated signalling in cancer cells», Nature Reviews Cancer, 13, 51-65.

[16] FLOWERS M., FABRIÁS G., DELGADO A., CASAS J., ABAD J.L. eta CABOT M.C. 2012. «C6-ceramide and targeted inhibition of acid ceramidase induce synergistic decreases in breast cancer cell growth», Breast cancer research and treatment, $\mathbf{1 3 3}, 447-458$.

[17] ZHU W., WANG X., ZHOU Y. eta WANG H. 2014. «C2-ceramide induces cell death and protective autophagy in head and neck squamous cell carcinoma cells», International journal of molecular sciences, 15, 3336-3355.

[18] ATILLA-GOKCUMEN G.E., MURO E., RELAT-GOBERNA J., SASSE S., BEDIGIAN A., COUGHLIN M.L., GARCIA-MANYES S. eta EGGERT U.S. 2014. «Dividing cells regulate their lipid composition and localization», Cell, 156, 428-439.

[19] ALJOHANI A.J., MUNGUBA G.C., GUERRA Y., LEE R.K. eta BHATTACHARYA S.K. 2013. «Sphingolipids and ceramides in human aqueous humor», Molecular vision, 19, 1966-1984.

[20] KOLESNICK R. 2002. «The therapeutic potential of modulating the ceramide/sphingomyelin pathway», The Journal of clinical investigation, 110, 3-8.

[21] KOLESNICK R.N. 1987. «1,2-Diacylglycerols but not phorbol esters stimulate sphingomyelin hydrolysis in GH3 pituitary cells», The Journal of biological chemistry, 262, 16759-16762.

[22] MERRILL A., SERENI A., STEVENS V., HANNUN Y., BELL R. eta KINKADE J. 1986. «Inhibition of phorbol ester-dependent differentiation of human promyelocytic leukemic (HL-60) cells by sphinganine and other long-chain bases», The Journal of biological chemistry, 261, 12610-12615.

[23] WERTZ P.W. eta DOWNING D.T. 1983. «Ceramides of pig epidermis: structure determination», Journal of lipid research, 24, 759-765.

[24] NOVGORODOV S.A., WU B.X., GUDZ T.I., BIELAWSKI J., OVCHINNIKOVA T.V., HANNUN Y.A. eta OBEID L.M. 2011. «Novel pathway of ceramide production in mitochondria: thioesterase and neutral ceramidase 
Bingen G. Monasterio, Aritz B. García-Arribas, Alicia Alonso, Felix M. Goñi

produce ceramide from sphingosine and acyl-CoA», The Journal of biological chemistry, 286, 25352-25362.

[25] CHATTERJEE S. 1994. «Neutral sphingomyelinase action stimulates signal transduction of tumor necrosis factor-alpha in the synthesis of cholesteryl esters in human fibroblasts», The Journal of biological chemistry, 269, 879-882.

[26] GOÑI F.M., MONTES L.R. eta ALONSO A. 2012. «Phospholipases C and sphingomyelinases: Lipids as substrates and modulators of enzyme activity», Progress in lipid research, 51, 238-266.

[27] CARRER D.C. eta MAGGIO B. 1999. «Phase behavior and molecular interactions in mixtures of ceramide with dipalmitoylphosphatidylcholine», Journal of lipid research, 40, 1978-1989.

[28] BUSTO J.V., FANANI M.L., DE TULLIO L., SOT J., MAGGIO B., GOÑI F.M. eta ALONSO A. 2009. «Coexistence of immiscible mixtures of palmitoylsphingomyelin and palmitoylceramide in monolayers and bilayers», Biophysical journal, 97, 2717-2726.

[29] MONTES L.R., RUIZ-ARGUELLO M.B., GOÑI F.M. eta ALONSO A. 2002. «Membrane restructuring via ceramide results in enhanced solute efflux», The Journal of biological chemistry, 277, 11788-11794.

[30] SISKIND L.J., KOLESNICK R.N. eta COLOMBINI M. 2002. "Ceramide channels increase the permeability of the mitochondrial outer membrane to small proteins», The Journal of biological chemistry, 277, 26796-26803.

[31] GOÑI F.M., SOT J. eta ALONSO A. 2014. «Biophysical properties of sphingosine, ceramides and other simple sphingolipids», Biochemical Society transactions, 42, 1401-1408.

[32] VEIGA M.P., ARRONDO J.L.R., GOÑI F.M. eta ALONSO A. 1999. «Ceramides in phospholipid membranes: effects on bilayer stability and transition to nonlamellar phases», Biophysical journal, 76, 342-350.

[33] CONTRERAS F.X., VILLAR A.V., ALONSO A., KOLESNICK R.N. eta GOÑI F.M. 2003. «Sphingomyelinase activity causes transbilayer lipid translocation in model and cell membranes», The Journal of biological chemistry, 278, 37169-37174.

[34] AXPE E., GARCÍA-ARRIBAS A.B., MUJIKA J.I., MÉRIDA D., ALONSO A., LOPEZ X., GARCIA J.A., UGALDE J.M., GOÑI F. eta PLAZAOLA F. 2015. «Ceramide increases free volume voids in DPPC membranes», $R S C$ $A d v, \mathbf{5}, 44282-44290$.

[35] CREMESTI A.E., GONI F.M. eta KOLESNICK R. 2002. «Role of sphingomyelinase and ceramide in modulating rafts: do biophysical properties determine biologic outcome?», FEBS letters, 531, 47-53.

[36] ALONSO A. eta GOÑI F.M. 2018. «The Physical Properties of Ceramides in Membranes», Annual review of biophysics, 47, 633-654.

[37] SOT J., ARANDA F.J., COLLADO M., GOÑI F.M. eta ALONSO A. 2005. «Different effects of long-and short-chain ceramides on the gel-fluid and lamellar-hexagonal transitions of phospholipids: a calorimetric, NMR, and xray diffraction study», Biophysical journal, 88, 3368-3380. 
Esfingolipidoak eta kolesterola, egitura lipidoak baino gehiago

[38] PHILLIPS M.C., LADBROOKE B.D. eta CHAPMAN D. 1970. «Molecular interactions in mixed lecithin systems», Biochimica et biophysica acta, 196, $35-44$.

[39] OLDFIELD E. eta CHAPMAN D. 1972. «Dynamics of lipids in membranes: Heterogeneity and the role of cholesterol», FEBS letters, 23, 285-297.

[40] SINGER S.J. eta NICOLSON G.L. 1972. «The fluid mosaic model of the structure of cell membranes», Science, 175, 720-731.

[41] ENGELMAN D.M. 2005. «Membranes are more mosaic than fluid», $\mathrm{Na}$ ture, 438, 578-580.

[42] GOÑI F.M. 2014. «The basic structure and dynamics of cell membranes: an update of the Singer-Nicolson model», Biochimica et biophysica acta, 1838, 1467-1476.

[43] BAGATOLLI L.A. eta MOURITSEN O.G. 2013. «Is the fluid mosaic (and the accompanying raft hypothesis) a suitable model to describe fundamental features of biological membranes? What may be missing?», Frontiers in plant science, 4.

[44] PLASENCIA I., NORLEN L. eta BAGATOLLI L. 2007. «Direct visualization of lipid domains in human skin stratum corneum's lipid membranes: effect of $\mathrm{pH}$ and temperature», Biophysical journal, 93, 3142-3155.

[45] DE LA SERNA J.B., PEREZ-GIL J., SIMONSEN A.C. eta BAGATOLLI L.A. 2004. «Cholesterol rules direct observation of the coexistence of two fluid phases in native pulmonary surfactant membranes at physiological temperatures», Journal of Biological Chemistry, 279, 40715-40722.

[46] PATRA S.K., ALONSO A., ARRONDO J.L. eta GOÑI F.M. 1999. «Liposomes containing sphingomyelin and cholesterol: detergent solubilisation and infrared spectroscopic studies», Journal of Liposome Research, 9, 247260.

[47] MCINTOSH T.J., SIMON S.A., NEEDHAM D. eta HUANG C.H. 1992. «Structure and cohesive properties of sphingomyelin/cholesterol bilayers», Biochemistry, 31, 2012-2020.

[48] LÖNNFORS M., DOUX J.P., KILLIAN J.A., NYHOLM T.K. eta SLOTTE J.P. 2011. «Sterols have higher affinity for sphingomyelin than for phosphatidylcholine bilayers even at equal acyl-chain order», Biophysical journal, 100, 2633-2641.

[49] SLOTTE J.P., YASUDA T., ENGBERG O., AL SAZZAD M.A., HAUTALA V., NYHOLM T.K. eta MURATA M. 2017. «Bilayer interactions among unsaturated phospholipids, sterols, and ceramide», Biophysical journal, 112, 1673-1681.

[50] RAMSTEDT B. eta SLOTTE J.P. 2002. «Membrane properties of sphingomyelins», FEBS letters, 531, 33-37.

[51] HONIGMANN A., MUELLER V., HELL S.W. eta EGGELING C. 2013. «STED microscopy detects and quantifies liquid phase separation in lipid membranes using a new far-red emitting fluorescent phosphoglycerolipid analogue», Faraday Discuss, 161, 77-89; discussion 113-150. 
Bingen G. Monasterio, Aritz B. García-Arribas, Alicia Alonso, Felix M. Goñi

[52] KUSUMI A., FUJIWARA T.K., MORONE N., YOSHIDA K.J., CHADDA R., XIE M., KASAI R.S. eta SUZUKI K.G. 2012. «Membrane mechanisms for signal transduction: the coupling of the meso-scale raft domains to membrane-skeleton-induced compartments and dynamic protein complexes», Seminars in cell \& developmental biology, 23, 126-144.

[53] PINTO S.N., SILVA L.C., FUTERMAN A.H. eta PRIETO M. 2011. «Effect of ceramide structure on membrane biophysical properties: the role of acyl chain length and unsaturation», Biochimica et biophysica acta, 1808, 2753-2760.

[54] SLOTTE J.P. 2013. «Molecular properties of various structurally defined sphingomyelins-correlation of structure with function», Progress in lipid research, 52, 206-219.

[55] JIMENEZ-ROJO N., SOT J., BUSTO J.V., SHAW W.A., DUAN J., MERRILL A.H., JR., ALONSO A. eta GONI F.M. 2014. «Biophysical properties of novel 1-deoxy-(dihydro)ceramides occurring in mammalian cells», Biophysical journal, 107, 2850-2859.

[56] ZUELLIG R.A., HORNEMANN T., OTHMAN A., HEHL A.B., BODE H., GUNTERT T., OGUNSHOLA O.O., SAPONARA E., GRABLIAUSKAITE K., JANG J.H., UNGETHUEM U., WEI Y., VON ECKARDSTEIN A., GRAF R. eta SONDA S. 2014. «Deoxysphingolipids, novel biomarkers for type 2 diabetes, are cytotoxic for insulin-producing cells», Diabetes, 63, 1326-1339.

[57] LONE M.A., SANTOS T., ALECU I., SILVA L.C. eta HORNEMANN T. 2019. «1-Deoxysphingolipids», Biochimica et biophysica acta. Molecular and cell biology of lipids, 1864, 512-521.

[58] VIEIRA C.R., MUNOZ-OLAYA J.M., SOT J., JIMENEZ-BARANDA S., IZQUIERDO-USEROS N., ABAD J.L., APELLANIZ B., DELGADO R., MARTINEZ-PICADO J., ALONSO A., CASAS J., NIEVA J.L., FABRIAS G., MANES S. eta GONI F.M. 2010. «Dihydrosphingomyelin impairs HIV-1 infection by rigidifying liquid-ordered membrane domains», Chemistry \& biology, 17, 766-775.

[59] MATÉ S., BUSTO J.V., GARCÍA-ARRIBAS A.B., SOT J., VAZQUEZ R., HERLAX V., WOLF C., BAKÁS L. eta GOÑI F.M. 2014. «N-Nervonoylsphingomyelin $(\mathrm{C} 24: 1)$ prevents lateral heterogeneity in cholesterol-containing membranes», Biophysical journal, 106, 2606-2616.

[60] BUSTO J.V., SOT J., REQUEJO-ISIDRO J., GOÑI F.M. eta ALONSO A. 2010. «Cholesterol displaces palmitoylceramide from its tight packing with palmitoylsphingomyelin in the absence of a liquid-disordered phase», Biophysical journal, 99, 1119-1128.

[61] SOT J., IBARGUREN M., BUSTO J.V., MONTES L., GOÑI F.M. eta ALONSO A. 2008. «Cholesterol displacement by ceramide in sphingomyelin-containing liquid-ordered domains, and generation of gel regions in giant lipidic vesicles», FEBS letters, 582, 3230-3236.

[62] BUSTO J.V., GARCIA-ARRIBAS A.B., SOT J., TORRECILlAS A., GOMEZ-FERNANDEZ J.C., GOÑI F.M. eta ALONSO A. 2014. «Lamellar 
Esfingolipidoak eta kolesterola, egitura lipidoak baino gehiago

gel $\left(\mathrm{L}_{\mathrm{b}}\right)$ phases of ternary lipid composition containing ceramide and cholesterol», Biophysical journal, 106, 621-630.

[63] COSENTINO K. eta GARCÍA-SÁEZ A.J. 2014. «Mitochondrial alterations in apoptosis», Chemistry and physics of lipids, 181, 62-75.

[64] ZHANG Q., TAMURA Y., ROY M., ADACHI Y., IIJIMA M. eta SESAKI H. 2014. «Biosynthesis and roles of phospholipids in mitochondrial fusion, division and mitophagy», Cellular and molecular life sciences: CMLS.

[65] BASAÑEZ G., SOANE L. eta HARDWICK J.M. 2012. «A new view of the lethal apoptotic pore», PLoS biology, 10, e1001399.

[66] GARCÍA-ARRIBAS A.B., BUSTO J.V., ALONSO A. eta GOÑI F.M. 2015. «Atomic force microscopy characterization of palmitoylceramide and cholesterol effects on phospholipid bilayers: a topographic and nanomechanical study», Langmuir, 31, 3135-3145.

[67] GARCÍA-ARRIBAS A.B., AXPE E., MUJIKA J.I., MÉRIDA D., BUSTO J.V., SOT J., ALONSO A., LOPEZ X., GARCÍA J.Á., UGALDE J.M., PLAZAOLA F. eta GOÑI F.M. 2016. «Cholesterol-Ceramide Interactions in Phospholipid and Sphingolipid Bilayers As Observed by Positron Annihilation Lifetime Spectroscopy and Molecular Dynamics Simulations», Langmuir, 32, 5434-5444.

[68] GARCÍA-ARRIBAS A.B., ALONSO A. eta GOÑI F.M. 2016. «Cholesterol interactions with ceramide and sphingomyelin», Chemistry and physics of lipids, 199, 26-34.

[69] MONTES L.R., LOPEZ D.J., SOT J., BAGATOLLI L.A., STONEHOUSE M.J., VASIL M.L., WU B.X., HANNUN Y.A., GOÑI F.M. eta ALONSO A. 2008. «Ceramide-enriched membrane domains in red blood cells and the mechanism of sphingomyelinase-induced hot-cold hemolysis», Biochemistry, 47, 11222-11230.

[70] OWEN J.S., BRUCKDORFER K.R., DAY R.C. eta MCINTYRE N. 1982. «Decreased erythrocyte membrane fluidity and altered lipid composition in human liver disease», Journal of lipid research, 23, 124-132.

[71] GARCÍA-ARRIBAS A.B., AHYAYAUCH H., SOT J., LÓPEZGONZÁLEZ P.L., ALONSO A. eta GOÑI F.M. 2016. «Ceramide-induced lamellar gel phases in fluid cell lipid extracts», Langmuir, 32, 9053-9063.

[72] GARCIA-RUIZ C., MARI M., COLELL A., MORALES A., CABALLERO F., MONTERO J., TERRONES O., BASAÑEZ G. eta FERNANDEZCHECA J.C. 2009. «Mitochondrial cholesterol in health and disease», Histology and histopathology, 24, 117-132.

[73] GERHOLD J.M., CANSIZ-ARDA Ş., LÕHMUS M., ENGBERG O., REYES A., VAN RENNES H., SANZ A., HOLT I.J., COOPER H.M. eta SPELBRINK J.N. 2015. «Human mitochondrial DNA-protein complexes attach to a cholesterol-rich membrane structure», Scientific reports, $\mathbf{5}$, 15292.

[74] DESAI R., FRAZIER A.E., DURIGON R., PATEL H., JONES A.W., DALLA ROSA I., LAKE N.J., COMPTON A.G., MOUNTFORD H.S. eta 
Bingen G. Monasterio, Aritz B. García-Arribas, Alicia Alonso, Felix M. Goñi

TUCKER E.J. 2017. «ATAD3 gene cluster deletions cause cerebellar dysfunction associated with altered mitochondrial DNA and cholesterol metabolism», Brain, 140, 1595-1610.

[75] MONTERO J., MORALES A., LLACUNA L., LLUIS J.M., TERRONES O., BASAÑEZ G., ANTONSSON B., PRIETO J., GARCIA-RUIZ C., COLELL A. eta FERNANDEZ-CHECA J.C. 2008. «Mitochondrial cholesterol contributes to chemotherapy resistance in hepatocellular carcinoma», Cancer research, $\mathbf{6 8}, 5246-5256$.

[76] LEE H., ROTOLO J.A., MESICEK J., PENATE-MEDINA T., RIMNER A., LIAO W.-C., YIN X., RAGUPATHI G., EHLEITER D. eta GULBINS E. 2011. «Mitochondrial ceramide-rich macrodomains functionalize Bax upon irradiation», PLoS One, 6, e19783.

[77] GARCÍA-ARRIBAS A.B., GONZÁLEZ-RAMÍREZ E.J., SOT J., ARESO I., ALONSO A. eta GOÑI F.M. 2017. «Complex Effects of 24:1 Sphingolipids in Membranes Containing Dioleoylphosphatidylcholine and Cholesterol», Langmuir, 33, 5545-5554.

[78] LEE W.-K. eta KOLESNICK R.N. 2017. «Sphingolipid abnormalities in cancer multidrug resistance: Chicken or egg?», Cellular signalling, 38, 134145.

[79] FERRARI E., BRUHN C., PERETTI M., CASSANI C., CAROTENUTO W.V., ELGENDY M., SHUBASSI G., LUCCA C., BERMEJO R. eta VARASI M. 2017. «PP2A controls genome integrity by integrating nutrientsensing and metabolic pathways with the DNA damage response», Molecular cell, 67, 266-281. e264.

[80] PARK W.-J., PARK J.-W., EREZ-ROMAN R., KOGOT-LEVIN A., BAME J.R., TIROSH B., SAADA A., MERRILL A.H., PEWZNER-JUNG Y. eta FUTERMAN A.H. 2013. «Protection of a ceramide synthase 2 null mouse from drug-induced liver injury role of gap junction dysfunction and connexin 32 mislocalization», Journal of Biological Chemistry, 288, 3090430916.

[81] OGRETMEN B. 2018. «Sphingolipid metabolism in cancer signalling and therapy», Nature Reviews Cancer, $\mathbf{1 8}, 33$. 